\title{
Diacronie
}

Studi di Storia Contemporanea

$N^{\circ} 8,4 \mid 2011$

Le sembianze di Clio: approcci alla storia

\section{Dimas Vaquero Peláez, Aragón con camisa negra. Las huellas de Mussolini}

\section{Matteo Tomasoni}

\section{(2) OpenEdition}

Journals

\section{Edición electrónica}

URL: http://journals.openedition.org/diacronie/3490

DOI: 10.4000/diacronie.3490

ISSN: 2038-0925

\section{Editor}

Association culturelle Diacronie

Referencia electrónica

Matteo Tomasoni, «Dimas Vaquero Peláez, Aragón con camisa negra. Las huellas de Mussolini »,

Diacronie [En línea], № 8, 4 | 2011, documento 10, Puesto en línea el 29 octubre 2011, consultado el 23 septiembre 2020. URL : http://journals.openedition.org/diacronie/3490 ; DOI : https://doi.org/

10.4000/diacronie.3490 


\section{RESEÑNA:}

\section{Dimas VAQUERO PELÁEZ, Aragón con camisa negra. Las huellas de Mussolini, Zaragoza, Rolde de Estudios Aragoneses, 2011, 365 pp.}

por Matteo TOMASONI*

«El Duce [...] tiene mucha razón en mostrarse satisfecho: la victoria en España lleva solamente el nombre de Mussolini»'. Con estas palabras, el 26 de enero de 1939, Galeazzo Ciano - Ministro de Asuntos Exteriores y cuñado del mismo Duce reflexionaba sobre la capitulación de Barcelona. Desde el comienzo del conflicto civil español la Italia fascista y la Alemania nazi declararon de inmediato su favor por la causa nacional y su propósito de derrocar el régimen republicano. Desde los primeros meses de combate, fueron sobre todo los italianos quienes enviaron todo tipo de material bélico, además de un cuantioso número de voluntarios destinados a luchar en los frentes ibéricos por la causa nacional y fascista. Una presencia, aquella italiana, que desde luego no pasó inadvertida.

En este libro el historiador aragonés Dimas Vaquero nos propone su última investigación con el intento de conciliar dos aspectos que desde hace tiempo caracterizan su principal línea de estudio: la Guerra Civil española en Aragón y la presencia militar italiana en España durante el conflicto. Con esta publicación el autor ha querido relacionar de forma más contundente estas dos temáticas; desde el análisis

${ }^{1}$ CIANO, Galeazzo, Diarios 1937-1943, Barcelona, Crítica, p. 245. 
propuesto en Credere, Obbedire, Combattere ${ }^{2}$, esta vez Vaquero vuelve a reconsiderar el papel de los italianos en España, pero con la atención de indagar más a fondo en su paso por Aragón. Lo que él define como "las huellas de Mussolini", bien representada por los voluntarios del CTV3 que en Zaragoza tuvieron su mando militar, no es más que la historia de aquellos rostros que en lo bueno y en lo malo participaron en el conflicto español convencidos de defender una causa justa y sagrada: la causa fascista.

La península italiana, geográficamente cercana y accesible desde los puertos del Levante, hacía tiempo era un punto de referencia para la sociedad, la economía y la política española. Durante la dictadura del general Miguel Primo de Rivera los dos países habían aumentado notablemente sus acuerdos de colaboración, ya que el mismo dictador se había declarado abiertamente 'simpatizante' del Duce4. Sin embargo, tras la proclamación de la Segunda República en España, las relaciones entre los dos países cambiaron de forma contundente. Como afirma Dimas Vaquero, Mussolini desde el cambio de régimen promovió un clima de "hostilidad" hacia España, ya que la idea del Mare Nostrum particularmente alabada por el Duce, se desvanecía tras las denuncias contra el expansionismo italiano provenientes de ciertos sectores de la política española. En 1936, la idea de contribuir a la causa nacional, apoyando deliberadamente a los generales rebeldes, favoreció la intervención armada del gobierno italiano con el envío de uno de los contingentes extranjeros más numerosos del conflicto: los legionarios del CTV. La intervención de los soldados de Mussolini empezó durante el otoño de 1936, aunque fue en los meses siguientes cuando se intensificó con más claridad la presencia de los italianos en suelo español. En principio los camice nere fueron enviados a lo largo de toda la península en distintos frentes, pero sería a partir de la primavera de 1937 cuando éstas fueron concentradas en Aragón y más precisamente en su capital, Zaragoza. Tras la caída del frente norte y la firma del Pacto de Santoña (agosto de 1937), los mandos nacionales decidieron concentrar las tropas italianas en el centro de Aragón, lugar estratégico en función de los futuros frentes que se abrirían hacia el sur (Teruel) y el este (Levante) peninsular.

La capital aragonesa, Saragozza para los italianos, se convirtió desde el otoño de 1937 en el principal lugar de concentración de las tropas legionarias italianas que

2 VAQUERO PELÁEZ, Dimas, Credere, Obbedire, Combattere. Fascistas italianos en la Guerra Civil española, Zaragoza, Mira, 2007.

3 Comando Truppe Volontarie.

4 Véase: TAMAMES, Ramón, Ni Mussolini ni Franco: la dictadura de Primo de Rivera y su tiempo, Barcelona, Planeta, 2008, 458. He tratado la cuestión de las relaciones políticoeconómicas entre España e Italia en: TOMASONI, Matteo, «L'Italia alla periferia del Mediterraneo. Le relazioni italo-spagnole tra XIX e XX secolo: politica, economia e società», Diacronie. Studi di Storia Contemporanea, 2011, pp. 13-17. 
obtuvieron el permiso de instalarse aquí para organizar sus divisiones en las semanas previas al comienzo de su participación en el frente de Aragón. Los italianos encontraron en el valle del Ebro el lugar más adecuado para su asentamiento, ya que la mayoría de sus unidades participó a las largas batallas que caracterizaron el frente de Aragón y que fueron coadyuvadas por la presencia de la "Aviación Legionaria" instalada en las islas Baleares. Además, según los relatos de entrevistas hechas por el autor a testigos de la época, los italianos no tardaron en mezclarse con la población local. El carácter abierto y típicamente mediterráneo, el idioma fácil de comprender, la demostración de ser soldados educados, respetuosos con los civiles y especialmente corteses con las mujeres aragonesas, los diferenciaron de la presencia - aunque más escasa - de voluntarios de la Luftwaffe alemana que, así como Mussolini, también Hitler había enviado a España como símbolo de amistad con el bando nacional5.

Desde Zaragoza y sus alrededores, los legionarios participaron en una numerosa serie de batallas y enfrentamientos entre los más sangrientos de toda la guerra civil. Firmemente convencidos de defender la ideología fascista y el orgullo del Duce, participaron a las distintas fases de la batalla de Teruel (diciembre 1937-febrero 1938). A continuación, gracias al material bélico enviado y de los bombardeos de la Aviación Legionaria, contribuyeron a la ruptura del frente de Aragón que con tanto sacrificio los republicanos habían defendido (marzo-abril 1938); fueron los primeros de los nacionales en pisar las playas del Levante (Vinaroz, abril de 1938); y finalmente participaron en la ofensiva sobre Cataluña que llevó a la ocupación de la ciudad de Barcelona (diciembre 1938-enero 1939).

Algunos autores han insistido en que la principal ayuda de Mussolini a Franco fue sobre todo el envío de un cuantioso número de aviones utilizados en los bombardeos sobre los frentes y las ciudades republicanas. El Estado italiano podía presumir de una aviación sin duda moderna, que había experimentado con éxito esta nueva técnica de guerra en los conflictos africanos de Libia y Etiopia. No sólo los resultados logrados habían sido satisfactorios, sino que además se observó que los bombardeos afectaban a la población civil alimentado un fuerte sentimiento de terror y pánico tras el paso de los aviones. Si en España esta técnica fue varias veces puesta en práctica con cierto éxito, no cabe duda de que el principal papel en el conflicto lo tuvieron las fuerzas terrestres. Durante, tras los combates e incluso años después el conflicto, Aragón se llenó de

\footnotetext{
$5 \mathrm{El}$ autor también especifica que la presencia de los italianos fue bien acogida para evitar la excesiva presencia de los moros, irregulares norteafricanos del ejército nacional que además de la fama de conocerse como soldados feroces, también contaban con la fama de ladrones y violadores. VAQUERO PELÁEZ, Dimas, Aragón con camisa negra. Las huellas de Mussolini, Zaragoza, Rolde de Estudios Aragoneses, 2011, p. 49.
} 
numerosos cementerios, monumentos fúnebres y placas que testimonian el elevado coste humano de los enfrentamientos.

Como demuestran los archivos consultados, Dimas Vaquero ha dedicado buena parte de su investigación a los cementerios de guerra que fueron ubicados en muchos de los pueblos aragoneses directamente afectados por el conflicto. En estos lugares de sepultura, los altos mandos italianos procuraron demostrar que también el máximo sacrificio era reconocido por la patria y por el fascismo como el mayor de los actos de heroísmo. Alrededor de estos cementerios se creó la 'mitificación del caído'; lugares donde los héroes de la patria descansaban seguros de haber caído por la gloria del Duce y la defensa del ideal fascista. Este aspecto poco conocido, quería ser el máximo ejemplo de celebración de los caídos, con las ofrendas y los discursos de los jerarcas llegados directamente desde Italia para fomentar también entre los aliados españoles la hermandad lograda con la Italia fascista. A menudo los proyectos de los cementerios presentaban enormes cruces, pilares de cemento, escaleras monumentales, 'fascios' intercalados por 'yugos y flechas', que recordaban la amistad italo-española. La misma población civil fue involucrada en este proceso de enfatización del 'amigo italiano' con la participación en masa tanto en los eventos conmemorativos como en los fúnebres, así como también lo testimonian las "madrinas de guerra”. En la capital zaragozana, se convertiría como centro de todas estas manifestaciones el Sacrario Militare Italiano, sin duda el mayor monumento funerario construido con el objetivo de reunir las salmas de los legionarios y celebrar su heroísmo en un lugar cargado de simbología fascista ${ }^{6}$.

Según el análisis de Vaquero, Zaragoza resultó ser por lo tanto el principal centro español de irradiación de la cultura, del idioma y sobre todo de la ideología de la Italia de Mussolini. Los principales seguidores de los fascistas italianos fueron sin duda los falangistas locales que tuvieron aquí la oportunidad de lograr un concreto acercamiento doctrinal. No obstante también la prensa, las instituciones (el autor recuerda la Casa del Fascio de Zaragoza) o la omnipresente simbología, fueron medios que fomentaron el fin político: educar, modelar e inculcar un fondo ideológico entre la población7. Curioso resulta un aspecto del análisis de Vaquero dedicado a la suerte de aquellos excombatientes que tras numerosas vicisitudes mantuvieron un vínculo 'particular' con

${ }^{6}$ El Sacrario fue financiado por el mismo gobierno de Mussolini y fue terminado en 1940. Aunque durante todo el franquismo albergase únicamente las salmas de los caídos fascistas, hace poco tiempo el gobierno italiano ha trasladado allí algunos voluntarios italianos de las Brigadas Internacionales, además de añadir una nueva placa con el nombre de todos los italianos que lucharon al lado de la República española. Semejante hecho ha desencadenado numerosas polémicas entre las familias de ambos bandos caídos; Dimas Vaquero ha intentado hacer una reflexión alrededor de esta espinosa cuestión. Véase VAQUERO PELÁEZ, Dimas, Aragón con camisa negra, cit., pp. 282-290.

7 VAQUERO PELÁEZ, Dimas, Aragón con camisa negra, cit., p. 250. 
Zaragoza. Es el caso de aquellos que se casaron, o los que se quedaron por trabajo, o también los que tras el fin de la Segunda Guerra Mundial decidieron escaparse de una Italia que ahora perseguía a los más destacados fascistas. Hoy en día ya sólo quedan algunos descendientes de aquellos italianos que convirtieron la capital aragonesa en su patria.

Otro aspecto analizado por Dimas Vaquero, es el estudio detallado de los lugares y la recuperación de parte de aquella "huella" dejada por los italianos desde 1937. La documentación utilizada a la que el autor ha procurado añadir planos, fotos, artículos de prensa, cartas de militares, etc., es un claro ejemplo de investigación no sólo archivística, sino también de fuerte dedición al 'trabajo de campo'. Resultan en sí muy interesantes la reproducción de inscripciones, monumentos, placas y símbolos que todavía permanecen visibles en toda la Comunidad, testigos del paso y del asentamiento de los legionarios italianos fieles a las consignas de su Duce; las expresiones "Chi si ferma è perduto" o "Duce a noi" bien reflejan el avance de estos soldados a lo largo de todo Aragón. Quizás el autor haya pecado de centrar su atención únicamente en la historia de los legionarios italianos, dejando de un lado la cooperación italo-española en los altos cargos, que a menudo demostró ser conflictiva a la hora de determinar la estrategia o la técnica a utilizar en combate; no sólo entre Franco y Mussolini (como ya muchos autores han podido comprobar), sino también entre los oficiales, y tal vez entre los mismos batallones que en Zaragoza tuvieron un estrecho contacto con el ejército nacional. Los medios de comunicación insistieron en afirmar que la amistad entre Italia y España se había oficializado a lo largo de la contienda; si desde un punto de vista militar no fue tan evidente, según el análisis de Vaquero esta sí fue muy fuerte entre los legionarios y la población local.

No cabe duda que estos temas tan delicados resultan ser hoy de difícil averiguación, ya que como bien explica el autor, la mayoría de los testigos sobrevivientes eran entonces demasiado jóvenes para darnos una respuesta concreta. El balance final por lo tanto no puede ser definitivo. Sin duda la presencia de los camice nere en Aragón contribuyó, tanto en su ayuda material cuanto humana, a obtener rápidos resultados favorables para el bando nacional; no sólo en la avanzada hacia el este peninsular, sino también en la propaganda y la difusión de un ideal que tenía como principal objetivo forjar una Nueva España. Los italianos no dudaron nunca de su Duce y éste no dejó que sus fascistas cayesen sin recibir un merecido reconocimiento por su sacrificio. $\mathrm{Y}$ a efecto de esta especial hermandad entre la Italia fascista y la España nacional, resulta por lo tanto verídica aquella inscripción que aún hoy se conserva en una pared del 
cementerio de Fraga (Huesca): «la sangre derramada por los legionarios italianos ha creado una indestructible amistad y confianza» 8 .

\footnotetext{
${ }^{8}$ Foto del autor, VAQUERO PELÁEZ, Dimas, Aragón con camisa negra, cit., p. 347.
} 


\section{* El autor}

Matteo Tomasoni, se ha licenciado en Historia Contemporánea en la Università di Bologna (2008) y desde 2009 es doctorando en la Universidad de Valladolid. Se ocupa de temas relacionados con la historia contemporánea de España, dedicándose especialmente al análisis de la Segunda República y de los movimientos pertenecientes a la extrema derecha española de los años Treinta: La conquista del Estado, JCAH, JONS y Falange Española. Colabora además en otros proyectos académicos y es miembro de la redacción de Diacronie.

URL: < http://www.studistorici.com/2008/o9/14/matteo-tomasoni/ >

\section{Per citare questo articolo:}

TOMASONI, Matteo, «RESEÑA: Dimas VAQUERO PELÁEZ, Aragón con camisa negra. Las huellas de Mussolini, Zaragoza, Rolde de Estudios Aragoneses, 2011, 365 pp.», Diacronie. Studi di Storia Contemporanea: Le sembianze di Clio: approcci alla storia, 29/10/2011, URL:<http://www.studistorici.com/2011/10/29/tomasoni_numero_8/ >

\section{Diacronie Studi di Storia Contemporanea $\beta$ www.diacronie.it}

Risorsa digitale indipendente a carattere storiografico. Uscita trimestrale. redazione.diacronie@hotmail.it

Comitato di redazione: Marco Abram - Giampaolo Amodei - Jacopo Bassi - Luca Bufarale - Alessandro Cattunar - Alice De Rensis Barbara Galimberti - Deborah Paci - Fausto Pietrancosta - Martina Sanna - Matteo Tomasoni - Luca Zuccolo

Diritti: gli articoli di Diacronie. Studi di Storia Contemporanea sono pubblicati sotto licenza Creative Commons 2.5 Possono essere riprodotti a patto di non modificarne i contenuti e di non usarli per fini commerciali. La citazione di estratti è comunque sempre autorizzata, nei limiti previsti dalla legge. 